\title{
A DECISION SUPPORT SYSTEM (DSS) FOR PRICE RISK MANAGEMENT IN VEGETABLE, CHINA
}

\author{
GUO Xiaomei ${ }^{1,3}$, FU Zetian ${ }^{2,3}$, MU Weisong ${ }^{2,3}$, ZHANG Xiaoshuan ${ }^{2,3, *}$ \\ (' College of Economic \& Management, China Agricultural University 209\#, Beijing, P. R \\ China, 100083) \\ $f^{2}$ Key Laboratory for Modern Precision Agriculture System Integration, Ministry of \\ Education, China, China Agricultural University, Beijing, P. R China, 100083) \\ $\beta$ College of Engineering, China Agricultural University 209\#, Beijing, P. R China, 100083) \\ * Corresponding author: Tel: +86-10-62736717 Fax: +86-10-62736717 \\ E-mail address: zhang_xiaoshuan@yahoo.com (ZH. Xiaoshuan) \\ Abstract: Vegetable industry plays a very important role in adjusting Agricultural \\ structure and increasing farmers' income. But vegetable industry is \\ characterized by a strong exposure to price risk, due to the increasingly \\ volatility of vegetable price. Price volatility in vegetable markets has been \\ wreaked havoc on the financial performance of producers and their customers. \\ So it is important to develop decision aids that help manage the risks of the \\ price fluctuate to vegetable growers and vegetable companies. A vegetable \\ price risk management decision support system (DSS_PRM) was developed \\ by China agricultural University. Based on questionnaire and interviews, we \\ analyze the decision problems and user needs. Then the architecture and \\ development of DSS_PRM were described. At last we discussed on problems \\ we had encountered during development and promotion.
}

Key words: China, DSS, Price risk management, Vegetable

\section{INTRODUCTION}

In China, vegetable has been the fastest growing subsector within the planting economy over the past two decades. The share of cultivated vegetable in total production has increased substantially from $2.22 \%$ in 1978 to $11.78 \%$ in 2003. As far as export is concerned, the export deals of vegetable amount to 35.11 ten thousand kilogram in 2002. It can affirm that the vegetable industry has the important function in agriculture economy 
and agricultural product export trade in China. So the concerned national departments have been attached importance to the vegetable industry.

However, this rapid growth of the vegetable has been accompanied by fluctuating prices. Vegetable prices are notoriously volatile, which can wreak havoc on the financial performance of vegetable producers and their customers (David W Cox, 1998). Coping with market uncertainty and price volatility is a constant challenge for the Chinese vegetable industry.

This anticipated price volatility underscores the need for managing price risk (Wes Ishmael, 2004). But producer cannot mitigate price risk because they lack of the knowledge of risk management. So it is evident for providing the help or tools for farmers on vegetable price risk management. Decision support systems for price risk management in vegetable typically useful to aid in managing price risk.

In this paper we describe the decision support systems for price risk management in vegetable (DSS-PRM). The rest of the paper is set out as follows. We give in Section 2 a brief overview of the conceptual framework about price risk and risk management. Section 3 describes the decision problem and user needs. Section 4 shows the system architecture and discusses the system implementation. The results and conclusions are presented in Section 5.

\section{PROBLEM DISCRIPTION}

\section{$2.1 \quad$ The process of price risk management}

A simple definition of a "price risk" is a problem that could cause some loss or threaten the success of our project owes to price volatility (Karl E. Wiegers, 1998). The definition presented is applicable to vegetable producers. Price uncertainty makes planning difficult, yet essential. Producers should take effect measures to manage price risk.

Risk management is the process of identifying, addressing, and eliminating these potential problems before they can damage our benefits (Karl E. Wiegers, 1998). The process of managing the price risk involves several stages. The process of risk management includes the following steps.

The first step involves assessing risk. It consists of risk identification, risk analysis and risk prioritization. Risk identification carry on qualitative analysis to the price risk in order to find out the influence factor that may produce the risk. Risk analysis involves examining how outcomes might change with modification of risk input variables. Risk prioritization helps the project focus on its most severe risks by assessing the risk exposure. 
The next step involves controlling risk. Risk control is the process of managing risks to achieve the desired outcomes. Risk management strategy produces a plan for dealing with each significant risk. Risk resolution is execution of the plans for dealing with each risk.

Finally, risk monitoring involves tracking your progress toward resolving each risk item.

\subsection{User need and the questionnaire}

To better meet the needs of vegetable grower and vegetable company, a questionnaire was designed to investigate their problems and needs. The questionnaires were sent to 120 farmers, 60 retailers from 13 regions in Shandong, Tianjin Provinces. Some interviews were also carried out afterwards to clarify the results collected. We learned that risks associated with price uncertainties turned out to be very important in the opinion of farmers (Jose, H Douglas, Valluru, Ram S K, 1994). Table 1 identifies the intended constituencies for the system along with samples of their decision making needs.

\section{Table 1. Requirements for the ideal decision support systems}

An effective DSS-PRM should have the potential to eliminate or mitigate price risk by

- Quantify the price risk

- Identify the most severe source of price risk of vegetable

- Offer the effective method of price risk management

- Be available at multi means and requires low skill and training, moreover, cost is affordable for users.

- Have a friendly and intuitive interface easy to use and communication method.

\section{THE SYSTEM ARCHITECTURE}

The problem description presented in the previous section indicates that the price risk management problem can be decomposed into four critical subproblems: price risk measure, the main source of price risk identification, price risk management method offering and user feedback. Therefore, the structure of price risk management consists of four main subsystems: measure subsystem, prioritization subsystem, management subsystem and response subsystem. Each of the subsystems contributes to the overall functionality of the system. It has different objectives and can be modeled and solved by different techniques appropriate for each. It is obviously that we do not absolutely obey the process of risk management above. In this system, we only consider the measure, prioritization, management of vegetable price risk because they are the most important needs to the users. 
The user interface is responsible for the interaction between the system and its users, especially ascertaining user need and obtaining commands and management of the input/output data and their display. The more detail of each of the subsystems is described below.

\subsection{The measure subsystem}

The measure system is used to assess the level of price risk. It consists of data collection module and measure module.

1) Data collection module. The data collection module is responsible for gathering data from a multitude of producers and preparing the data sets for the measure module. The data is directly entered by hand. All the data are stored in database. The database plays an important role and is responsible for storing all the information needed for price risk quantification in DSSPRM.

2) Measure module. The data measure module which quantifies the price risk is the key component of the subsystem. Actually, volatility can be indicated in a number of ways; here we use the measure of coefficient of variation (the standard deviation divided by the mean) (George Flaskerud; William Wilson; Bruce Dahl, 2002). The coefficient of variation is especially useful to measure the volatility of different commodity prices. It is a simple and effective method that quantifies price risk. Figure 1 shows the interface of price risk measure.

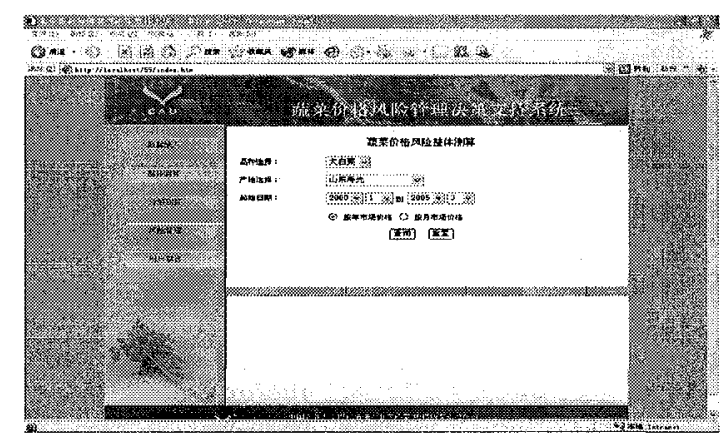

Figure 1. Interface of risk measure

\subsection{The prioritization subsystem}

This module is responsible for identifying the most severe price risk factor of vegetable. That is, focusing on the most important price risk factor by assessing the risk exposure. Once the exposures to several price risk 
factors have been identified and quantified, it is possible to analyze which ones represent the largest sources of price risk for the vegetable producer. Applying to factor decomposition model (Christopher Barrett, Winnie K.Luseno, 2004), it may be easier to estimate the probable degree of a variety of price risk factors. It also consists of data collection module and measure module. According the simple method of price risk decomposition, producer price risk is attributable to volatile inter-market margins, intraday variation, intra-week (day of week) variation, or terminal market price variability. They represent separately informational/institutional risk, local market risk, basis risk and terminal market risk.

\subsection{The management subsystem}

The management subsystem is responsible for offering the optimal method of avoid the price risk. It consists of a knowledge database. In the knowledge database, there are a plenty of price risk management strategies. In fact, vegetable producers have a wide variety of tools to manage price risk available to them. However, there is no clear-cut best strategy for all producers or one that works consistently over time. It is unlikely that one alternative will consistently be the best choice.

Selecting optimal risk management strategy of vegetable price should be based on a thorough comparison of available alternatives. In the risk management subsystem, we will offer the best risk mitigate strategy by fulfilling the operation.

\subsection{The response subsystem}

Cooperation and feed-back mechanism with the end users is also essential in this collaborative process to help improve the quality of information sought for remove price risk. We can receive the feedback information and opinions of the users by the response subsystem.

\section{THE IMPLEMENTATION OF DSS-PRM}

The structure of information system adopted B/S (Browser/Server/), which is able to better apply information system to network production. There are many solutions for developing the web-based systems. We adopted the solution by Microsoft, i.e. ASP (Actives server pages) + MS Access + IIS (Internet Information Server) due that it is prone to master by non-professional system developer. 


\section{DISCUSSION AND CONCLUSION}

This paper reports a research attempt in developing a decision support system for price risk management in vegetable products market. The system is able to measure the degree of price risk and detect the most severe risk source in the vegetable products market via integration of risk measure and evaluation. The system is also offer the most effective price risk management method to the user.

However, there are still some shortages should be addressed, such as:

Internal problems relate to data update and deficiencies in the factor decomposition model. Even though we can obtain data from some vegetable product company, it proves difficult given that the research and development team is not an official governmental body. These factors resulted in slow adoption and willingness to participate in using the system.

On-going research is to integrate the proposed system with a decision support system that can assist participants in selecting the most effective plans.

\section{ACKNOWLEDGEMENTS}

This program is supported by EU Aided Asia IT\&C under Grand No. CN/ASIA-IT\&C/005(89099) and partly by NSFC (National Nature Science Foundation of China) under Grant No. 70133001. We also would like to thank many domain experts from China Agriculture University.

\section{REFERENCES}

[1] Christopher Barrett, Winnie K.Luseno, Decomposing producer price risk: a policy analysis tool with an application to northern Kenyan livestock markets, Food Policy, 2004, Vol.29, pp. 393-405.

[2] David W Cox, Paper company hedging programs uncomplicated to design, implement, Pulp \& Paper, 1998.6, pp. 97-99.

[3] George Flaskerud; William Wilson; Bruce Dahl, Managing canola price risk, The Journal of the ASFMRA; 2002; ProQuest Agriculture Journals, pp. 53-63.

[4] Jose, H Douglas, Valluru, Ram S K, Insights from the Crop Insurance Reform Act of 1994, Agribusiness, 1997, Vol.13, Iss. 6, pp. 587-596.

[5] Karl E. Wiegers, Know Your Enemy: Software Risk Management, Process Impact, www.processimpact.com.

[6] Wes Ishmael, Manage your price risk, Beef, 2004.2, Vol.40, Iss, 6, pp. 6. 